\title{
STUDY OF STRUCTURE AND PROPERTIES OF SELF-FLUXING ALLOY AFTER MODIFYING WITH NANOSTRUCTURED AND MICRON-SIZED POWDERS OF CUBIC BORON NITRIDE AND HIGH PRESSURE AND HIGH TEMPERATURE TREATMENT
}

\author{
Senyut V.T. ${ }^{1}$, Vityaz P.A. ${ }^{2}$, Val kovich I.V. ${ }^{1}$,Kheifetz M.L. ${ }^{3}$, Kolmakov A.G. ${ }^{4}$ \\ 1 Joint Institute of Mechanical Engineering of NAS of Belarus, Minsk, Belarus, vsenyut@tut.by \\ 2 Presidium of the National Academy of Sciences of Belarus, Minsk, Belarus, vitiaz@presidium.bas-net.by \\ 3 «NPO Center» OJSC, National Academy of Sciences of Belarus, Minsk, Belarus, mlk-z@mail.ru \\ ${ }^{4}$ A.A. Baykov Institute of Metallurgy and Materials Science, Russian Academy of Sciences, Moscow, Russia, \\ agk10@bk.ru
}

\begin{abstract}
The structural features and microhardness of sintered at high pressure and high temperature with the addition of nano- and micron-sized powders of cubic BN (cBN) self-fluxing nickel alloy $P G$ SR4 are studied. Based on the experiments, the modes of high pressure and high temperature treatment are established. The optimal content of the nanostructured cBN additive is determined, at which the material with the highest microhardness is formed. It is shown that the microhardness of the material with the addition of micron-sized cBN is 1.5-2 times lower than that for the samples with the same content of nanostructured $c B N$.
\end{abstract}

Keywords: PG-SR4 self-fluxing nickel alloy, mechanical activation, nanostructured and micron-sized cBN powders, modifying.

\section{Introduction}

Self-fluxing nickel alloys of the Ni-Cr-B-Si system are widely used in the technology of wearresistant coatings for the restoration and hardening of tribological conjugation parts at elevated contact loads and temperatures [1].The fluxing elements boron and silicon included in the alloy contribute to lowering the melting temperature and deoxidizing the metal surface of the part with the formation of strong diffusion bonds between the coating and substrate materials during melting of the sprayed coating. For example, the coatings of powders of self-fluxing alloys deposited by a gas-flame method with reflow have high physical and mechanical characteristics: strength up to 400-500 MPa, hardness within 25-64 HRC, low friction coefficient, high wear and corrosion resistance $[2,3]$. The most famous and widespread method of increasing the wear resistance of selffluxing alloys is the development of composite materials using reinforcing additives in the form of carbides, borides, and transition metal nitrides [4]. Modifying by solid refractory compounds allows to change the structure of self-fluxing alloys effectively, contributes to its dispergation and increase the physical and mechanical properties, tribological and operational characteristics of materials based on them [5].

\section{Formulation of the problem}

Along with the refractory nanopowders such as $\mathrm{Al}_{2} \mathrm{O}_{3}, \mathrm{SiC}, \mathrm{TiB}_{2}, \mathrm{TiC}, \mathrm{WC}$, and others, single and multicarbide and oxide mechano-composites are also quite efficiently used as modifying additives for self-fluxing alloys [6,7]. In this regard, it can be assumed that the use of cubic BN $(\mathrm{cBN})$, which has high physical and mechanical properties [8], will significantly increase hardness and wear resistance and, accordingly, increase the life time of products based on self-fluxing alloys instead of traditional additives of refractory compounds. In addition, BN will serve as a source of 
boron, contributing to the formation of hardening phases of chromium and nickel borides in the heat treatment process.

It is known that the application of pressure during the synthesis of the materials based on cBN prevents the reverse phase transformation of $\mathrm{cBN}$ into a graphite-like (hexagonal) modification of $\mathrm{BN}(\mathrm{hBN})$ and provides the best combination of structural characteristics and strength parameters of the alloy [9]. The purpose of the work is to study of the structure and microhardness of samples of self-fluxing nickel alloy of the Ni-Cr-B-Si system obtained by high pressure and high temperature (HPHT) treatment, with the addition of nano- and micron powders of cubic BN.

\section{The research technique.}

For the manufacture of experimental samples, the powder of self-fluxing alloy PG-SR4 (GOST $21448-75)$ is chosen. It contains $15-18 \% \mathrm{Cr} ; 3.0-4.5 \% \mathrm{Si} ; 2.8-3.8 \% \mathrm{~B}$; $0.6-1.0 \% \mathrm{C}$; no more than $5 \% \mathrm{Fe}$; and the rest is $\mathrm{Ni}$. Two types of $\mathrm{cBN}$ are used as an additive: nanostructured powder with a particle size of 100-200 nm and micron-sized powder with a grain size of the main fraction within 40-60 $\mu \mathrm{m}$. A mixture based on the PG- SR4 alloy with the addition of nano- or micron-sized cBN for HPHT treatment is obtained by mixing and mechanical activation (MA) in the attritor of the initial powders, their compacting and preliminary sintering in a protective atmosphere, dispersing the compacts to agglomerates and sieving the agglomerates into fractions. For HPHT treatment the agglomerate fraction with the size of $100-315 \mu \mathrm{m}$ is used.

HPHT treatment of composite powders is carried out in an "anvil with a hole" high-pressure apparatus at pressures of $1.5-2.0 \mathrm{GPa}$ and temperatures of $1000-1350{ }^{\circ} \mathrm{C}$ during $20 \mathrm{~s}$. First, the "cold" compression of the mixture, placed in a special container made of lithographic stone, is carried out, and then the mixture is heated under pressure by direct electric current.

The studies of cross-sections of samples are performed by optical microscopy using Micro200 metallographic microscope (Planar OJSC, Belarus). The microhardness of the samples is measured with a PMT-3 microhardness tester by Vickers diamond indenter with a load of $50 \mathrm{~g}$. $\mathrm{X}$-ray analysis is performed with Bruker D8 ADVANCE diffractometer in $\mathrm{Cu}-\mathrm{K} \alpha$ radiation in an automatic recording mode.

\section{Results and discussion}

Figure 1 shows the appearance of the initial micron-sized and nanostructured cBN powders used as a modifying additive to prepare PG-SR4 and cBN composite powders. Composition powders in form of the agglomerates based on PG-SR4 with the addition of 2.5-10 vol. \% micronsized or nanostructured $\mathrm{cBN}$ have preliminary been prepared as described above.

Figure 2 shows the surface structure of the compacts made of PG-SR4 powder with the addition of nanostructured (Fig. 2 a) and micron-sized cBN (Fig. 2 b) after MA and sintering. The analysis of the surface of the compacts after sintering (Fig. 2) shows that the samples based on PGSR 4 and nanostructured cBN has low porosity and are characterized by uniform structure. As a result of MA and sintering, nanostructured $\mathrm{cBN}$ is evenly distributed between particles of selffluxing alloy and is fixed on their surface, leading to the formation of a composite powder with a cladding structure (Fig. 2 a). The compacts made of the composite powder PG-SR4 and micronsized cBN after MA and sintering (Fig. 2b) consist of agglomerated particles of self-fluxing alloy and $\mathrm{cBN}$ crystals and have a much more porous and inhomogeneous dendritic type structure. Then the compacts are mechanically dispersed, and the resulting agglomerates of composite powders are sieved into fractions. As a result of the HPHT-treatment of the agglomerated composite powders with the additions of nano- and micron-sized $\mathrm{cBN}$, the cylindrical samples with a diameter of 10 $\mathrm{mm}$ and a height of $8 \mathrm{~mm}$ are obtained. Then they are polished at the ends with diamond paste. In the process of preparation of the cross-sections, it is defined that the material is highly brittle, and this does not allow preparing high-quality cross-sections on them to conduct further research. 


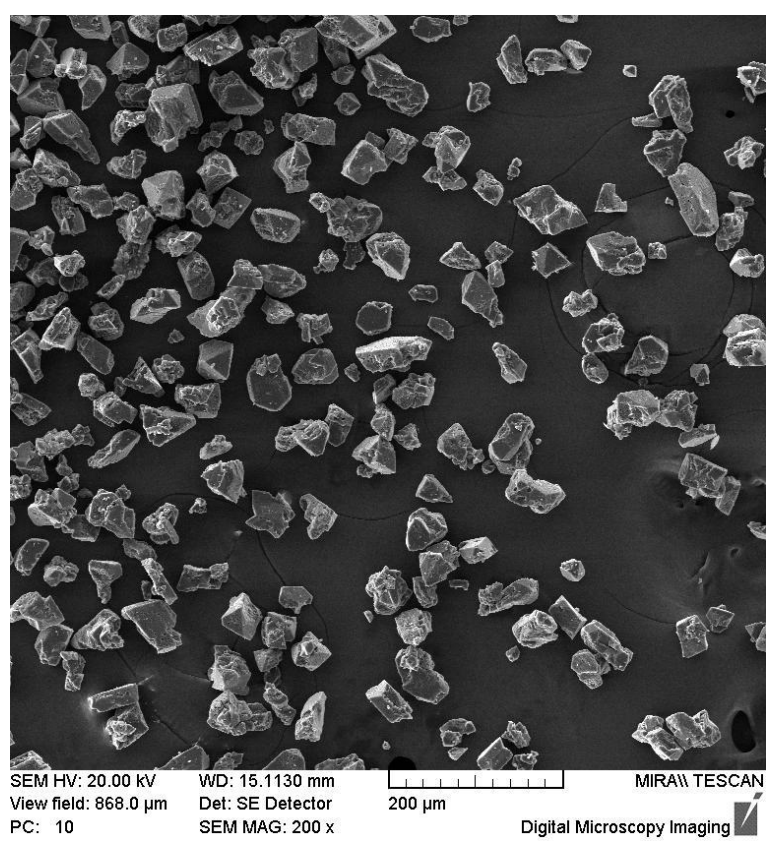

a)

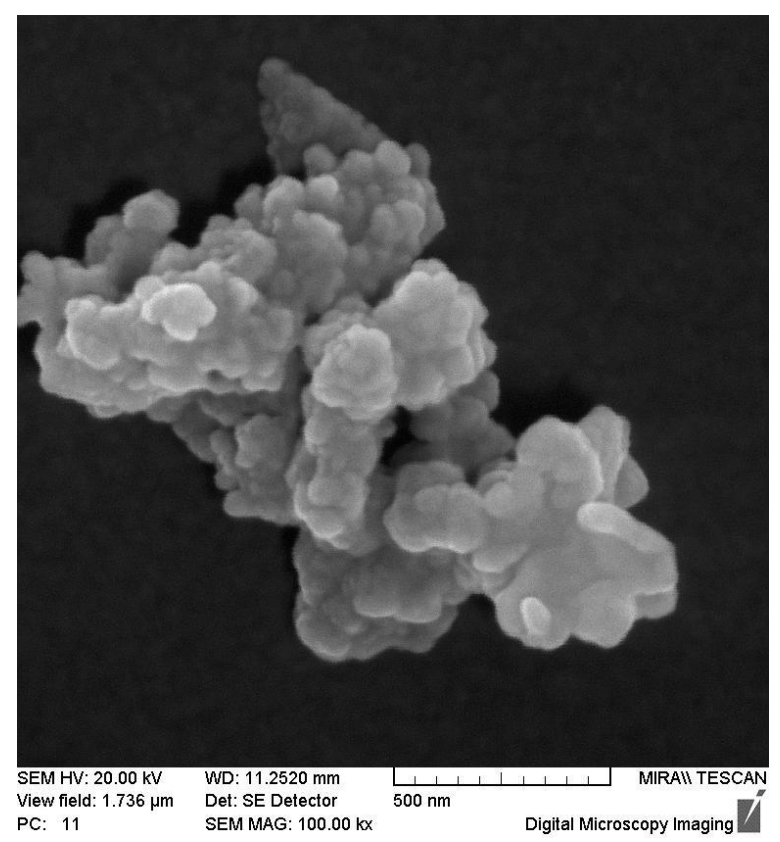

b)

Fig.1. Initial cBN powders used as additives: micron-sized powder (a); nanostructured powder (b).

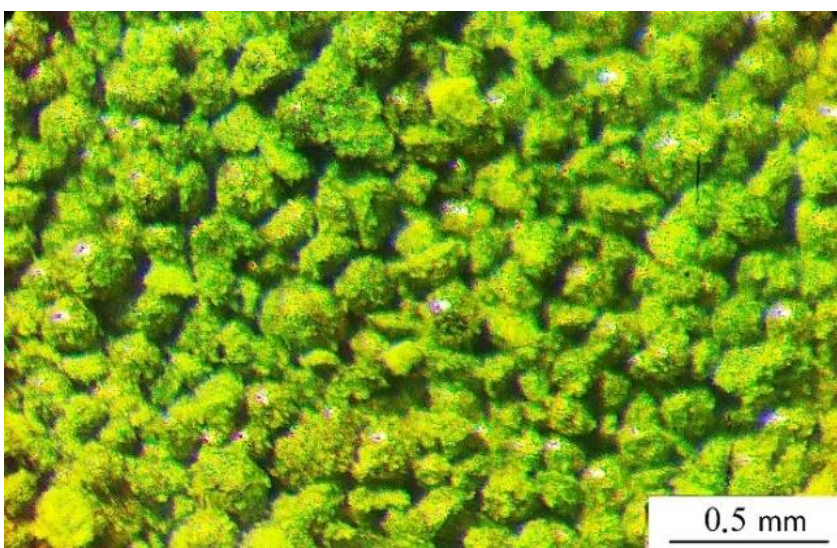

a)

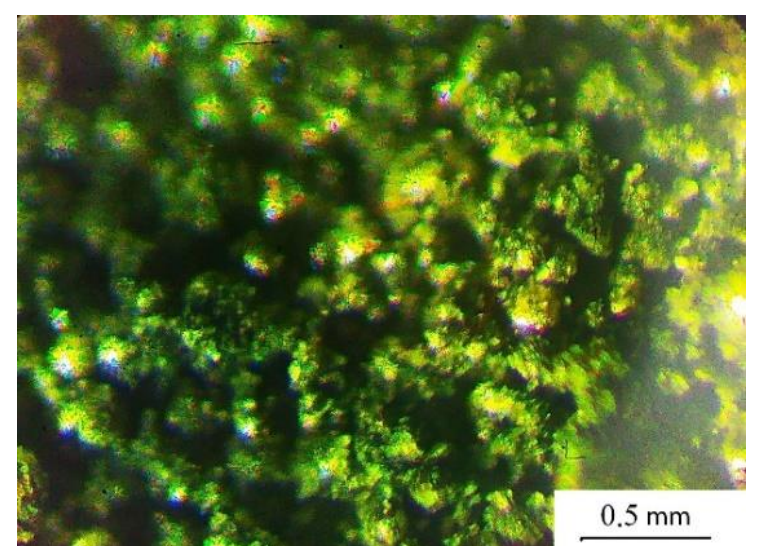

b)

Fig.2.The surface of the compacts based on PG-SR4 powder after MA and sintering in a protective atmosphere: PG- SR4 and nanostructured cBN (a);PG-SR4 and micron-sized cBN (b)

Therefore, in order to reduce the brittleness of the material, the powder of the initial PG-SR4 alloy of the same fraction has been additionally introduced into the mixture before the HPHT treatment. Figures $3 \mathrm{a}$ and $3 \mathrm{~b}$ show the photographs of the surface of the samples based on selffluxing alloy with the addition of nanostructured cBN after HPHT treatment. It has been established that the main structural components of the sintered material are the matrix self-fluxing alloy based on a solid solution of $\mathrm{Cr}$ in $\mathrm{Ni}$, the chromium boride phase $\mathrm{Cr} 2 \mathrm{~B}$, as well as $\mathrm{BN}$ particles, that are evenly distributed in the material. In the material obtained at temperatures up to $1200{ }^{\circ} \mathrm{C}$, the aggregates of $\mathrm{cBN}$ particles are uniformly distributed in the matrix and can be clearly seen on the background of the matrix alloy in the form of point inclusions of submicron sizes and individual polyhedral particles of 5-10 $\mu \mathrm{m}$ in size (Fig. 3a) formed as a result of recrystallization of nanostructured $\mathrm{cBN}$ [9]. In the samples of the material obtained at temperatures above $1200{ }^{\circ} \mathrm{C}$, boron nitride is present in the form of light particles with a size of 5-15 $\mu \mathrm{m}$ of lamellar form that is characteristic of the graphite-like phase of BN. Moreover, with increasing the temperature of the HPHT treatment, the growth of individual alloy particles above $300 \mu \mathrm{m}$ can be marked (Fig. 3b). 
Microhardness measurements of the samples show that for the material containing nanostructured $\mathrm{cBN}$ in the range of 2.5-3.5 vol. \%, microhardness values are 11.8-13.7 GPa, and this is $18-32 \%$ higher than that for the samples containing no additives. An increase in concentration of nanostructured $\mathrm{cBN}$ promotes embrittlement of the material, and an increase in temperature leads to a decrease in microhardness due to the developing reverse phase transformation of $\mathrm{cBN}$ into a graphite-like modification of $\mathrm{BN}$.

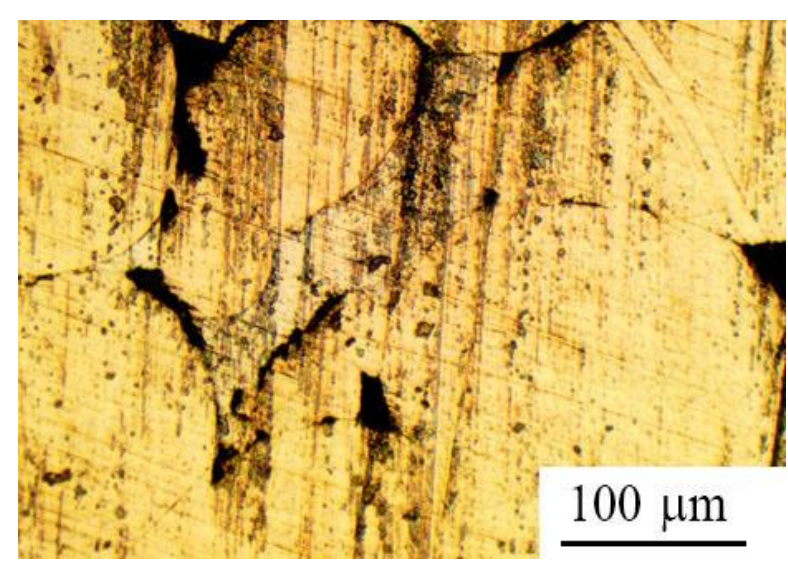

a)

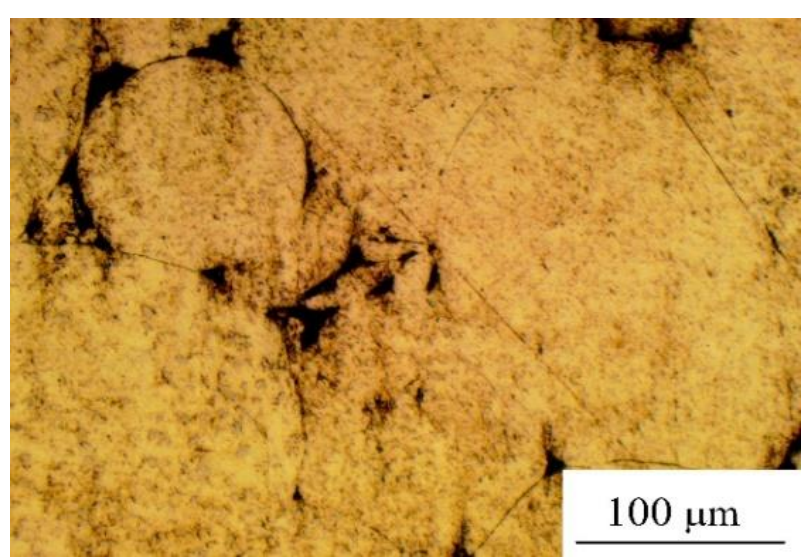

b)

Fig.3. The surface structure of the samples based on self-fluxing alloy PG-SR4 and nanostructured cBN after the HPHT treatment: The temperature of the HPHT treatment is $1100{ }^{\circ} \mathrm{C}(\mathrm{a}) ; 1350{ }^{\circ} \mathrm{C}(\mathrm{b})$

Figure 4 shows the surface of the samples based on self-fluxing alloy with the addition of micron-sized cBN after the HPHT treatment. The analysis of the material structure shows that $\mathrm{cBN}$ crystals are mainly between the alloy particles (Fig. 4a). At the same time, together with the initial $\mathrm{cBN}$, the material contains small fragment-type cBN crystals formed as a result of crushing of larger particles under pressure (Fig. 4b). In addition to particles of the indicated types, cBN crystals with a size of 5-8 $\mu \mathrm{m}$ of a pyramidal habit are also observed. They could be formed as a result of dissolution and crystallization of $\mathrm{cBN}$ from the melt under pressure (Fig. 4b). Moreover, as in the case of the use of nanostructured $c \mathrm{BN}$ additives, a graphite-like $\mathrm{BN}$ is formed in the material containing micron-sized cBN with an increase in temperature (Fig. 4c).

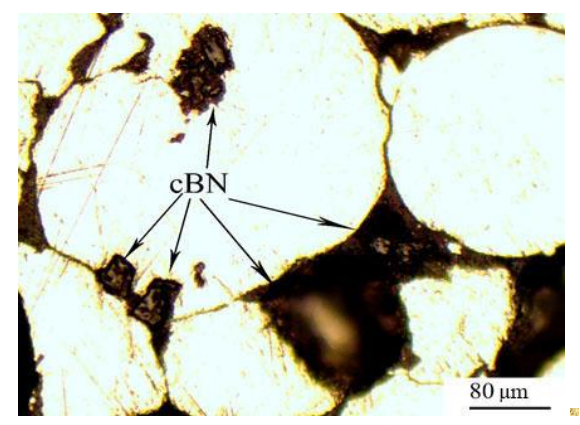

a)

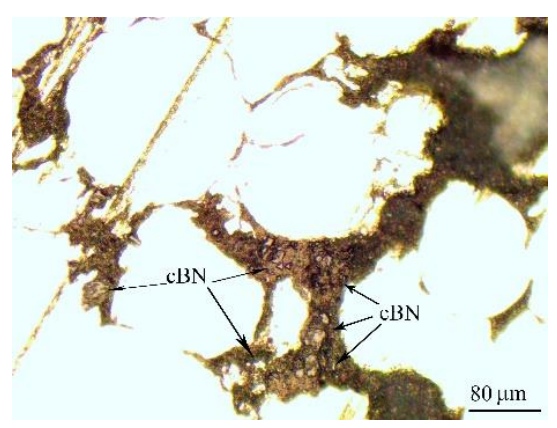

b)

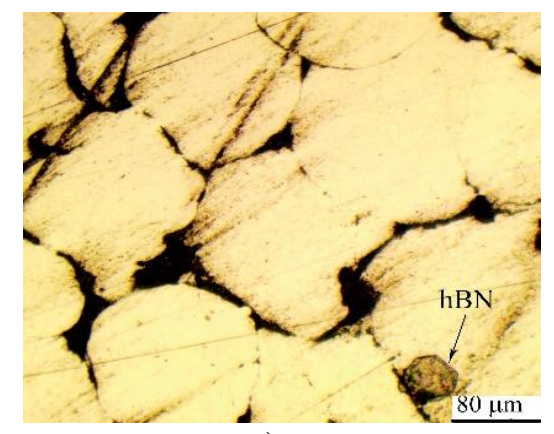

c)

Fig.4.The surface structure of the samples based on self-fluxing alloy PG-SR4 and micron-sized cBN after the HPHT treatment: large cBN crystals along the boundaries of the alloy particles (a); small cBN crystals formed as a result of crushing and recrystallization of primary $\mathrm{cBN}$ crystals (b); formation of graphite-like $\mathrm{BN}(\mathrm{c})$

The maximum microhardness of PG-SR4 samples with the addition of micron-sized powder $\mathrm{cBN}$ is in the range of 6.4-7.1 GPa, and this is 1.5-2 times lower than that for the material with the same content of nanostructured cBN sintered at the same parameters of the HPHT treatment. 


\section{Conclusion}

The results show the promise of using of $\mathrm{cBN}$ nanostructured powder as a modifying additive for chromium-nickel self-fluxing alloys. It is shown that nanostructured $\mathrm{cBN}$ is distributed in a matrix based on self-fluxing alloy in the form of inclusions of submicron sizes and individual polyhedral particles up to $10 \mu \mathrm{m}$ in size, while $\mathrm{cBN}$ micron-sized powder crystals are located between self-flux alloy particles.

In the process of HPHT treatment of the PG-SR4 alloy with the addition of $c B N$, the latter undergoes a number of structural and phase transformations: recrystallization of $\mathrm{cBN}$, crushing of large cBN crystals, formation of secondary $\mathrm{cBN}$ crystals as a result of dissolution and recrystallization of the initial $\mathrm{cBN}$, and the formation of a graphite-like $\mathrm{BN}$.

Microhardness of the material with the addition of $2.5-3.5$ vol. \% of nanostructured $\mathrm{cBN}$ is $11.8-13.7 \mathrm{GPa}$, and this is $18-32 \%$ higher than that for the samples containing no additives of $\mathrm{cBN}$. The samples with the addition of the micron-sized $\mathrm{cBN}$ powder are characterized by microhardness values in the range of 6.4-7.1 GPa, and this is 1.5-2 times lower than that for the material with the same content of nanostructured $\mathrm{cBN}$.

\section{Acknowledgements \\ The work is supported by the Belarusian Republican and Russian Foundations of Basic Research (Project code is T18R-183).}

\section{REFERENCES}

1 Ilyuschenko A.Ph., Shevtsov A.I., Astashinsky V.M. et al. High-power pulse processing of thermal coatings based on a self-fluxing alloy and modified by solid high-melting compounds: research and modeling. High Temperature Material Processes. 2017, Vol. 21, No. 3, pp. 203-223. DOI:10.1615/HighTempMatProc.2017024942

2 Vityaz P.A., Ivashko V.S., Ilyushchenko A.F., Shevtsov A.I., Manoilo E.D. Theory and practice of coating. Minsk, Belarus. Science, 1998, 583 p. [in Russian]

3 Manoilo E.D., Onashchenko F.E. Gas-flame coating of self-fluxing alloys - new aspects. Mechanical Engineer. 2012, No. 4, pp. 6-9. [in Russian]

4 Kulik A.Ya., Borisov Yu.S., Mnukhin A.S. Thermal spraying of composite powders. Leningrad, Mechanical Engineering, 1985, 197 p. [in Russian]

5 Ilyushchenko A.F., Shevtsov A.I., Astashinsky V.M. et al. Investigation of the wear resistance and antifriction properties of gas-thermal coatings based on NiCrBSi alloy, modified with solid refractory compounds and pulsed high-energy impacts. Powder metallurgy. Minsk, 2018, No. 41. pp. 221-228. [in Russian]

6 Lyakhov N. Z., Talako T.L., Grigoryeva T.F. Influence of mechanical activation on the processes of phase and structure formation during self-propagating high-temperature synthesis. Novosibirsk, Parallel, 2008, 168 p. [in Russian]

7 Sobachkin A.V., Nazarov I.V., Yakovlev V.I. Morphology of coatings from multi-component, previously mechanically activated powders of SPS-composites. Metal processing. 2012, No 3 (56), pp. 141144. [in Russian]

8 Golubev A.S., Kurdyumov A.V., Pilyankevich A.N. Boron nitride. Structure, properties, production. Kiev, Nauk. Dumka, 1987, 200 p. [in Russian]

9 Vityaz P.A., Senyut V.T., Kheifets M.L., Kolmakov A.G. Production of alumo-matrix composite material modified by nanostructured cubic boron nitride. Proceeding of the NAS of Belarus, Phys.-Tech. Ser. 2018, Vol. 63, No 3, pp. 271-279. DOI.org/10.29235/1561-8358-2018-63-3-271-279. 